\title{
War Trauma, Anxiety, and Resilience among University Students in the Gaza Strip
}

\author{
Abdel Aziz Mousa Thabet ${ }^{1 *}$ and Said Mohammed Abu Sultan ${ }^{2}$ \\ ${ }^{1}$ Child and Adolescent Psychiatry, Al Quds University, School of Public-consultant Psychiatrist at Child and Family Training and Counseling Center- \\ Gaza-Palestine
}

${ }^{2}$ Ministry of Health, Palestine

*Corresponding author: Abdel Aziz Mousa Thabet, MB, MD, PhD, Emeritus Professor of Child and Adolescent Psychiatry, Al Quds University, School of Public-consultant Psychiatrist at Child and Family Training and Counseling Center-Gaza-Palestine, Tel: +4377771978; E-mail: abdelazizt@hotmail.com

Received date: Oct 10, 2016; Accepted date: Nov 21, 2016; Published date: Nov 30, 2016

Copyright: (C) 2016 Thabet AAM et al. This is an open-access article distributed under the terms of the Creative Commons Attribution License, which permits unrestricted use, distribution, and reproduction in any medium, provided the original author and source are credited.

Citation: Thabet AAM, Sultan SMA. War Trauma, Anxiety, and Resilience among University Students in the Gaza Strip. Clin Psychiatry. $2016,2: 4$.

\section{Abstract}

The aims of this study were to identify the types of the traumatic experiences, to find the type of resilience factors, anxiety trait and state occurrence, and to determine the relationship between exposure to the traumatic experiences, resilience and trait and state among university students. It is a descriptive analytical study; the sample consisted of randomly selected 399 university students enrolled in the main four universities in Gaza Strip (Al-Aqsa, Al-Azhar, Al-Quds Open and Islamic University) at the second semester of the academic year 2012-2013. We used five questionnaires to collect the data; a predesigned Sociodemographic sheet, Gaza Traumatic Events Checklist, the State-Trait Anxiety Inventory, and Connor-Davidson Resilience Scale.

This study showed that the most commonly reported traumatic events were watching mutilated bodies on TV $(92.7 \%)$, witnessing the shelling and destruction of another's home $(47.37 \%)$, witnessing firing by tanks and heavy artillery at neighbors' homes $(47.12 \%)$, and being forced to move from home to a safer place during the war $(42.86 \%)$. Mean total traumatic events was 4.72 . Anxiety state mean was 46.62 and anxiety trait mean was 36.22 . The most common resilience concepts (most of the time/all the time) were: God can help (91.7\%), things happen for a reason $(90.3 \%)$, and I am proud of my achievements $(85.2 \%)$. Male students had significantly more total resilience, more personal competence and more trust in one's instincts than female students. The results showed that there was a significant correlation between total traumatic events and anxiety state and trait. The results showed that there was no significant correlation between total traumatic events and total resilience, but there was a positive significant correlation between total traumatic events and trust in one's instincts, tolerance of negative affect and strengthening effects. On the other hand, there was a significant correlation between total traumatic events and spiritual domain. There was a significant correlation between anxiety state and total resilience and its subscales except in spiritual dimension.
Our conclusion was exposure to previous traumatic events due to Gaza war had long-term negative effects on Palestinian university students which increased their mental health problems. We recommend that students affair should show brief students the nature of the course, the institutional ethos, the subjects that they will be taught and aspects relating to assignments, examinations, evaluation and other academic requirements, and should also provide therapeutic interventions for university students who suffer from anxiety.

Keywords: Anxiety trait and state; Resilience; Trauma; University students

\section{Introduction}

Epidemiological studies such as the National Comorbidity Survey (NCS) reported that more than $50 \%$ of surveyed adults have experienced at least one traumatic event during their lifetime [1].

Previous studies in Palestinian society in the Gaza Strip showed that Palestinians reported traumatic events mean ranged from 4-10 events [2-4]. Thabet et al. [4] in their study of a sample consisted of 381 randomly selected universities students in Gaza Strip showed that the mean traumatic events reported by university students were 10 traumatic events. The commonest reported traumatic events were watching mutilated bodies on TV (94.5\%), hearing shelling of the area by artillery (92.4\%), hearing the loud voice of drone's motors (87.4\%), and inhalation of bad smells due to bombardment (78.7\%). In Iraq Freh [5] in his study of 224 Iraqi young adults found that their age ranged from 12 to 23 years, found that $74.6 \%$ of the participants reported having experienced at least one highmagnitude traumatic event in their lifetime as a result of the invasion. Of the total sample, $57.4 \%$ involved a family member being killed, $28.7 \%$ a family member being injured, and $13.7 \%$ had had their house demolished. Participants who reported having a family member injured were noted to have higher levels of depression and anxiety than comparable participants who had a family member killed. 
Anxiety has been defined as 'an unpleasant emotional state or condition which is characterized by subjective feelings of tension, apprehension and worry, and by activation or arousal of the autonomic nervous system' [6]. Spielberger et al. [6] suggested that we are living in an 'age of anxiety' and it is often claimed that people are more prone to anxiety now than they were previously. Anxiety is the top presenting concern among college students worldwide (41.6\%), followed by depression (36.4\%) and relationship problems (35.8\%) [7]. A recent survey on the universities in China found that the rate of anxiety was $11.7 \%$ [8]. Thabet [3] in a descriptive analytic study, the sample consisted of randomly selected 399 university students from main four universities in Gaza Strip showed that $10.3 \%$ of males and $13.8 \%$ of females had anxiety. No statistically significant differences in mean anxiety according to gender.

Lu et al. [9] in a study investigated the prevalence of mental health problems and their predictors in a sample of 1048 Chinese college freshmen from Shanghai. Regarding anxiety, $46.85 \%$ of students had anxiety problems. Resilience is seen as a characteristic that enables individuals not only to overcome adversity but also to thrive when facing a crisis [10]. The last two decades have witnessed a growing interest in factors that are associated with psychological resilience following exposure to trauma $[11,12]$. Many people are exposed to loss or potentially traumatic events at some point in their lives, and yet they continue to have positive emotional experiences and show only minor and transient disruptions in their ability to function. Unfortunately, because much of psychology's knowledge about how adults cope with loss or trauma has come from individuals who sought treatment or exhibited great distress, loss and trauma theorists have often viewed this type of resilience as either rare or pathological [13].

Resilience is not construed as a trait, though numerous individual and family attributes are associated with the emergence of positive adaptation in the presence of threats and elevated risk [14]. Instead, resilience refers to the capacity for adapting successfully in the context of adversity, typically inferred from evidence of successful adaptation following significant challenges or system disturbances. Resilience "in action" can be observed most directly when the processes of adaptation to a major disturbance are in progress. Yet resilience can be also inferred from evidence that the system is "likely" to respond well when given the resources and adaptive capabilities available to the system. Efforts to prepare individuals, families, communities, and other systems for anticipated challenges often have the goal of building system capacity for positive responses to disturbances [15]. For the purpose of the present study, resilience will be defined as the tendency to overcome factors that place one at risk for psychological dysfunction and to adjust positively in the aftermath of a potentially traumatic event [16].

Juma and Thabet [17] in a descriptive analytic study consisting of randomly selected 399 university students from the main four universities in Gaza Strip found that the most frequent coping strategies were finding comfort in religious beliefs $(78.2 \%)$, thinking about what steps to take $(71.4 \%)$, and learning to live with situation (67.7\%). Also, Thabet and Thabet [4] investigating randomly selected 502 subjects from 5 areas of the Gaza Strip found that Palestinians used religious ways of coping with the stress and trauma, and that $98 \%$ said God is helping all the time, they were proud of their achievements, and had strong sense of purpose in their life. The aims of this study were 1) To identify the types of the traumatic experiences, 2) to highlight the type of resilience, and occurrence of anxiety trait and state, and 3) to determine the relationship between exposure to the traumatic experiences, resilience and anxiety state and trait among university students.

\section{Method}

\section{Participants}

Participants were 399 Palestinian university students enrolled in four universities in Gaza strip (Al-Aqsa University, Al-Al-Azhar University, Al-Quds Open University and Islamic University). Two hundred and thirty two of the participants $(58.1 \%)$ were females and 167 (41.9\%) were males.

\section{Measures}

\section{A predesigned socio- demographic sheet}

This questionnaire included; gender, age, name of the university, place of residence, and family monthly income.

\section{The Gaza traumatic events checklist}

This described the most common traumatic experiences the population could have faced during the 2008-2009 war on Gaza. This checklist consists of 18 items covering three domains of events typical of the war on Gaza: (1) Hearing traumatic events (items numbers 1-2 include hearing about killing of relatives or friends). (2) Witnessing trauma (items number 3-8, experiencing witnessing of home demolition, and killing of others). (3) Personal experiences (items number 9-18, being personally the target of violence, being shoot, injured, or beaten up by soldiers). The respondents rated whether they had been exposed to each of these events as (0) 'no' or (1) 'yes'. A total score was estimated. The scale had high internal consistency $(\alpha=0.76)$ and split half was 0.85 .

\section{Connor-Davidson resilience scale}

The CD-RISC was developed for clinical practice as a measurement of coping ability in the face of adversity $[18,19]$. It consists of 25-items with each item rated on a 5-point Likert scale, ranging from 0 (not true at all) to 4 (true nearly all the time). Higher total scores indicate greater resilience.

The internal consistency of the scale was calculated using Chronbach's alpha, and was high $(\alpha=0.88)$ [4]. In this study the Cronbach's Alpha coefficient for the whole scale was high $(\alpha=0.93)$.

\section{The State-trait anxiety inventory (STAI)}

The STAI consists of two identical 20-item subscales: one measuring state anxiety and the other measuring trait anxiety 
[6]. For the state scale, individuals are asked to rate their anxiety "in the moment" and for the trait scale, individuals are asked to rate their anxiety "in general." Participants rate items (e.g., "I feel nervous and restless") on the state version on a 4-point scale ranging from 1 (not at all) to 4 (very much so) and rate items on the trait version on a 4-point scale ranging from 1 (almost never) to 4 (almost always).

Internal consistencies of scores range from $\alpha=0.65-0.96$, with a mean of $\alpha=0.91$ for the state scale of the STAI and range from $\alpha=0.72-0.96$ with a mean of $\alpha=0.89$ for the trait scale of the STAI. Test-retest correlations of scores (various time periods) range from $r=0.34-0.96$ with a mean of $r=0.70$ for the state scale of the STAI and range from $r=0.82-0.94$ with a mean of $r=0.88$ for the trait scale of the STAI [20]. In this study the Cronbach's alpha coefficient for the anxiety trait scale was $(\alpha=0.87)$ and Cronbach's alpha coefficient for the anxiety state scale was $(\alpha=0.78)$.

\section{Study Procedure}

The data were collected using randomly selected sample from four universities in Gaza Strip (Al-Aqsa University, Al-Al-Azhar University, Al-Quds Open University and Islamic University) after getting an official approval from each university.

An official approval from each university has been got in order to enter the university to implement the study, Helsinki Ethical committee (Ministry of Health) gave approval to carry out the study, informed written consents approval from each student has been got, this form included the purpose of the study, confidentiality information and some instruction, it also included statement about student right to participate or refuse.

The data was collected by four assistants professionals trained for four hours in data collection of this sample and criteria for selecting students in the second semester of the academic year 2012-2013. Each student has completed five questionnaires on 15 to 20 minutes; difficult questions if present were explained by data collectors. The data collection was done in two weeks.

\section{Statistical Analyses}

Statistical analyses were carried out using IBM SPSS Statistics version 20. Continuous variables were presented as $M \pm S D$ and categorical variables were expressed as frequencies (\%). The trauma, anxiety state and trait, and resilience scores of the participants were exhibited using the mean values and SD.

Spearman's correlation coefficient tested the association between trauma, anxiety trait and state, and resilience scores of the participants.

Prediction of resilience by trauma, anxiety state and trait, was tested by series of stepwise multiple linear regression analyses was conducted, with each traumatic events and anxiety state and trait entered as the predictor and total resilience score as the dependent variable. A two-tailed $p$ value $<0.05$ was considered statistically significant.

\section{Results}

\section{Socio-demographic of the study sample}

The sample consisted of 399 Palestinian university student's male and female living in Gaza strip (Al-Aqsa University, Al-Azhar University, Al-Quds Open University and Islamic University (Table 1). Two hundred and thirty two of the participants (58.1\%) were females and $167(41.9 \%)$ were males. One hundred and forty (35.1\%) of the participants were from The Islamic university, 93(23.3\%) were from Al-Aqsa university, 88(22.1\%) were from Open Al-Quds university, and 78(19.5\%) were from Al-Azhar university.

Ninety four (23.56\%) from university students of the study sample were from North Gaza, 206(51.63\%) were from Gaza, 78(19.55\%) were from Middle area, 13(3.26\%) were from Khan Younis and $8(2.01 \%)$ were from Rafah.

Table 1 Socio-demographic of the study sample ( $N=399)$.

\begin{tabular}{|c|c|c|}
\hline & $\mathbf{N}$ & $\%$ \\
\hline \multicolumn{3}{|l|}{ Sex } \\
\hline Male & 167 & 41.9 \\
\hline Female & 232 & 58.1 \\
\hline \multicolumn{3}{|l|}{ Age Mean $20.4(S D=1.42)$} \\
\hline \multicolumn{3}{|l|}{ Place of residence } \\
\hline North Gaza & 94 & 23.56 \\
\hline Gaza & 206 & 51.63 \\
\hline Middle area & 78 & 19.55 \\
\hline Khan Younis & 13 & 3.26 \\
\hline Rafah & 8 & 2.01 \\
\hline \multicolumn{3}{|l|}{ University enrolment } \\
\hline Islamic university & 140 & 35.1 \\
\hline Al-Aqsa university & 93 & 23.3 \\
\hline Open Al-Quds university & 88 & 22.1 \\
\hline Al-Azhar university & 78 & 19.5 \\
\hline \multicolumn{3}{|l|}{ Family income in (NIS) } \\
\hline *Less than 1000 NIS & 143 & 35.84 \\
\hline $1001-2000$ NIS & 111 & - \\
\hline $2001-3000$ NIS & 71 & 17.79 \\
\hline $3001-4000$ NIS & 46 & 11.53 \\
\hline More than 4000 NIS & 28 & 7.02 \\
\hline${ }^{*}$ Note $\$ 1$ US dollar $=380$ & & \\
\hline
\end{tabular}

Most of the family income of the university students of the study sample were less than 1000 NIS 143(35.84\%) , 111 family's income were from 1001-2000 NIS (27.82\%), 71 of the family's income were from 2001-3000 NIS (17.79\%), 46 of the family's 
income were from $3001-4000$ NIS (11.53\%) and 28 were more than 4000 NIS (7.02\%).

\section{Exposure to trauma}

The most commonly reported traumatic events were watching mutilated bodies in TV $(92.7 \%)$, witnessing the shelling and destruction of another's home (47.37\%), witnessing firing by tanks and heavy artillery at neighbors' homes (47.12\%), and being forced to move from home to a safer place during the war (42.86\%) as shown in Table 2. The mean total traumatic events was $4.72(\mathrm{SD}=3.09)$.

\section{Differences in traumatic events according to socio- demographic variables}

Independent t-test showed statistically significant gender differences, where male students experienced significantly more traumatic events than females $(t=6.49, p=0.001)$. One-way ANOVA was conducted in which total traumatic events was entered as dependent variable and other socio-demographic variables as independent variables. There were no significant differences in traumatic events resulting from war on Gaza according to the university of the study sample $(F=1.65, p=0.17)$.

\section{Anxiety state and strait}

Anxiety state: Anxiety state mean was $46.62(S D=7.67)$. There were no significant differences in Anxiety state according to sex of the study sample ( $t=1.57, p=0.11)$.

The results found that there were no significant differences in anxiety state resulting from war on Gaza according to the university ( $F=0.01, p=0.99)$. There were no significant differences in anxiety state according to the family income $(F=2.03, p=0.08)$.

Anxiety trait: Anxiety trait mean was $36.22(S D=11.43)$. The results found that there were significant differences in Anxiety trait according to sex of the study sample $(t=-2.23, p=0.02)$ in favor of females.

There were no significant differences in Anxiety trait resulting from war on Gaza according to the university of the study sample $(\mathrm{F}=1.854, \mathrm{p}=0.13)$.

Table 2 Frequency of traumatic events of the study sample.

\begin{tabular}{|c|c|c|c|}
\hline S.No & Items of traumatic events & Yes (\%) & No (\%) \\
\hline 1 & Watching mutilated bodies in TV & 92.73 & 7.27 \\
\hline 2 & Witnessed the shelling and destruction of other's homes & 47.37 & 52.63 \\
\hline 3 & Witnessing firing by tanks and heavy artillery at neighbors' homes & 47.12 & 52.88 \\
\hline 4 & Forced to move from home to a safer place during the war & 42.86 & 57.14 \\
\hline 5 & Deprivation from water or electricity during detention at home & 38.85 & 61.15 \\
\hline 6 & Being detained at home during incursions & 35.84 & 64.16 \\
\hline 7 & Witnessing killing of a friend & 28.57 & 71.43 \\
\hline 8 & Witnessing shooting of a friend & 27.57 & 72.43 \\
\hline 9 & Threaten by shooting & 27.57 & 72.43 \\
\hline 10 & Destroying of your personal belongings during incursion & 16.79 & 83.21 \\
\hline 11 & Witnessed the shelling and destruction of own home & 11.28 & 88.72 \\
\hline 12 & Witnessing shooting of a close relative & 9.02 & 90.98 \\
\hline 13 & Exposure to burn due to phosphorus bombs & 9.02 & 90.98 \\
\hline 14 & Shooting by bullets, rocket, or bombs & 8.77 & 91.23 \\
\hline 15 & Beating and humiliation by the army & 8.52 & 91.48 \\
\hline 16 & Threatened with death by being used as human shield by the army to move from home to home & 7.52 & 92.48 \\
\hline 17 & Threaten of being killed & 7.27 & 92.73 \\
\hline 18 & Witnessing killing of a close relative & 6.27 & 93.73 \\
\hline
\end{tabular}

Resilience in university students: The most common resilience items (most of the time/all the time) were:

God can help (91.7\%), things happen for a reason (90.3\%), and being proud of their achievement (85.2\%).
Means and standard deviation of resilience: For resilience, mean resilience was $64.54(S D=14.26)$, personal competence was 20.99(SD=5.67), trust in one's instincts was $15.32(S D=4.74)$, positive acceptance was $13.18(S D=3.23)$, control was 
$7.78(S D=2.48)$, and spiritual influences was $7.27(S D=1.36)$ as shown in Table 3.

Table 3 Mean and standard deviation of total resilience and its subscales.

\begin{tabular}{|l|l|l|}
\hline Variable & Mean & SD \\
\hline Total resilience & 64.54 & 14.26 \\
\hline Personal competence & 20.99 & 5.67 \\
\hline Trust in one's instincts & 15.32 & 4.74 \\
\hline Positive acceptance & 13.18 & 3.23 \\
\hline Control & 7.78 & 2.48 \\
\hline Spiritual influences & 7.27 & 1.36 \\
\hline
\end{tabular}

\section{Differences in resilience according to socio-} demographic variables

There were gender differences in resilience subscales. Male students had significantly more total resilience than females (Mean=66.49 vs. 63.19) $(t=2.29, p=0.02)$. Male students had significantly more personal competence than female students (Mean=21.63 vs. 20.53) ( $\mathrm{t}=1.9, \mathrm{p}=0.05)$, and trust in one's instincts (Mean=16.38 vs. 14.56$)(t=3.85, p=0.001)$ as shown in Table 4.

\section{Correlation coefficients between total traumatic events and anxiety state and trait, total resilience and its subscales}

Pearson correlation coefficient test was performed to find the relationship between trauma, anxiety trait and state, and resilience in universities students. The results showed a significant correlation between total traumatic events and

anxiety state and trait, and no correlation between traumatic events and anxiety trait was found $(r=0.14, P=0.004),(r=0.08$, $\mathrm{P}=0.07$ ) respectively (Table 5 ). The results found that there was no significant correlation between total traumatic events and total resilience $(r=0.06, P=0.10)$, but there was a positive significant correlation between total traumatic events and trust in one's instincts, tolerance of negative affect and strengthening effects $(r=0.14, p<0.01)$. On the other hand, there was a significant correlation between total traumatic events and spiritual domain $(r=-0.13, p<0.01)$. There was a positive significant correlation between anxiety state and total resilience and its subscales except in spiritual dimension $(r=0.28, p<0.01)$.

Table 4 Independent $t$ test comparing mean of resilience according to sex of the study sample.

\begin{tabular}{|c|c|c|c|c|c|c|}
\hline Variables & Sex & $\mathbf{N}$ & Mean & SD & $\mathbf{t}$ & $\mathbf{p}$ \\
\hline \multirow{2}{*}{ Total resilience } & Male & 167 & 66.49 & 15.06 & \multirow{2}{*}{2.29} & \multirow{2}{*}{0.02} \\
\hline & Female & 232 & 63.19 & 13.5 & & \\
\hline \multirow{2}{*}{$\begin{array}{l}\text { Personal } \\
\text { competence }\end{array}$} & Male & 167 & 21.63 & 5.65 & \multirow{2}{*}{1.9} & \multirow{2}{*}{0.05} \\
\hline & Female & 232 & 20.53 & 5.66 & & \\
\hline \multirow{2}{*}{$\begin{array}{l}\text { Trust in one's } \\
\text { instincts }\end{array}$} & Male & 167 & 16.38 & 4.84 & \multirow{2}{*}{3.85} & \multirow{2}{*}{0.001} \\
\hline & Female & 232 & 14.56 & 4.52 & & \\
\hline \multirow{2}{*}{$\begin{array}{l}\text { Positive } \\
\text { acceptance }\end{array}$} & Male & 167 & 13.35 & 3.49 & \multirow{2}{*}{0.93} & \multirow{2}{*}{0.35} \\
\hline & Female & 232 & 13.05 & 3.02 & & \\
\hline \multirow{2}{*}{ Control } & Male & 167 & 8.02 & 2.39 & \multirow{2}{*}{1.63} & \multirow{2}{*}{0.1} \\
\hline & Female & 232 & 7.61 & 2.54 & & \\
\hline \multirow{2}{*}{ Spiritual } & Male & 167 & 7.14 & 1.55 & \multirow{2}{*}{-1.53} & \multirow{2}{*}{0.12} \\
\hline & Female & 232 & 7.36 & 1.19 & & \\
\hline
\end{tabular}

Table 5 Correlation coefficients between total traumatic events and anxiety state and trait, total resilience and its subscales.

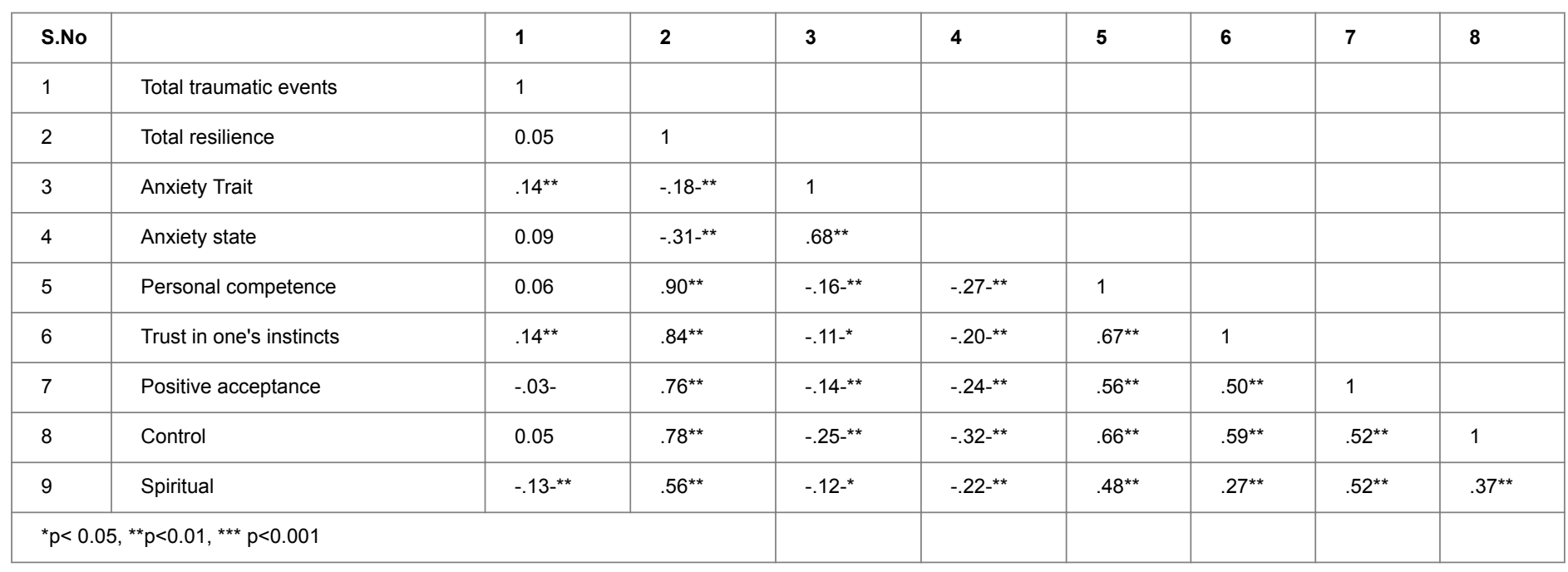


Prediction of anxiety state by traumatic events and other socioeconomic variables

In a multivariate regression model, each traumatic event, age, sex, place of residence, family monthly income were entered as an independent variables, with anxiety state as the dependent variable (Table 6). Beating and humiliation by the army was predicting anxiety state $(\beta=0.17, p=0.001)$ and family monthly income was negatively predicted anxiety state $(\beta=0.12, p=0.01)$.

Table 6 Multivariate regression model of each traumatic event with total anxiety state.

\begin{tabular}{|c|c|c|c|c|c|c|c|}
\hline & \multirow{2}{*}{$\begin{array}{l}\text { Unstandardized } \\
\text { Coefficients } \\
\text { B }\end{array}$} & \multirow[b]{2}{*}{$\begin{array}{l}\text { Std. } \\
\text { Error }\end{array}$} & \multirow{2}{*}{$\begin{array}{l}\text { Standardized } \\
\text { Coefficients } \\
\text { Beta }\end{array}$} & \multirow[b]{2}{*}{$\mathbf{t}$} & \multirow[b]{2}{*}{ p-value } & \multicolumn{2}{|c|}{$\begin{array}{l}95.0 \% \\
\text { Interval for B }\end{array}$} \\
\hline & & & & & & $\begin{array}{l}\text { Lower } \\
\text { Bound }\end{array}$ & $\begin{array}{l}\text { Upper } \\
\text { Bound }\end{array}$ \\
\hline (Constant) & 46.219 & 0.39 & & 118.61 & 0.001 & 45.45 & 46.99 \\
\hline Family monthly income & -0.76 & 0.301 & -0.12 & -2.527 & 0.012 & -1.351 & -0.169 \\
\hline Beating and humiliation by the army & 4.81 & 1.335 & 0.17 & 3.6 & 0.001 & 2.19 & 7.43 \\
\hline
\end{tabular}

\section{Prediction of resilience by traumatic events}

In a multivariate regression model, each traumatic event, age, sex, place of residence, family monthly income were entered as an independent variables, with total resilience as the dependent variable. Four traumatic events were significantly associated with total resilience: threatened with death by being used as human shield by the army to move from home to home negatively predicted resilience $(\beta=-0.22, p=0.001)$, witnessing shooting of a friend $(\beta=0.15 p=0.001)$, witnessing the shelling and destruction of other's home $(\beta=0.36, p=0.001)$, and hearing killing of a close relative $(\beta=0.13, p=0.002)$ were predictor factors for resilience (Table 7). Gender differences in prediction resilience was toward male $(\beta=0.11, p=0.02)$.

Table 7 Multivariate regression model of each traumatic event with total resilience.

\begin{tabular}{|c|c|c|c|c|c|c|c|}
\hline & \multirow{2}{*}{$\begin{array}{l}\text { Unstandardized } \\
\text { Coefficients } \\
\text { B }\end{array}$} & \multirow[b]{2}{*}{$\begin{array}{l}\text { Std. } \\
\text { Error }\end{array}$} & \multirow{2}{*}{$\begin{array}{l}\text { Standardized } \\
\text { Coefficients } \\
\text { Beta }\end{array}$} & \multirow[b]{2}{*}{$\mathbf{t}$} & \multirow[b]{2}{*}{ p-value } & \multicolumn{2}{|c|}{$\begin{array}{l}95.0 \% \text { Confidence } \\
\text { Interval for B }\end{array}$} \\
\hline & & & & & & $\begin{array}{l}\text { Lower } \\
\text { Bound }\end{array}$ & $\begin{array}{l}\text { Upper } \\
\text { Bound }\end{array}$ \\
\hline (Constant) & 59.89 & 0.93 & & 64.68 & 0.001 & 58.07 & 61.71 \\
\hline Sex & -3.11 & 1.374 & -0.11 & -2.263 & 0.024 & -5.811 & -0.409 \\
\hline $\begin{array}{l}\text { Threatened with death by being used as human } \\
\text { shield by the army to move from home to home }\end{array}$ & -11.51 & 2.52 & -0.22 & -4.56 & 0.001 & -16.47 & -6.55 \\
\hline Witnessing shooting of a friend & 4.43 & 1.56 & 0.15 & 2.84 & 0.001 & 1.36 & 7.49 \\
\hline $\begin{array}{l}\text { Witnessed the shelling and destruction of other's } \\
\text { home }\end{array}$ & 3.61 & 1.42 & 0.13 & 2.55 & 0.01 & 0.82 & 6.39 \\
\hline
\end{tabular}

\section{Discussion}

The study aimed to find the association between war traumatic experiences, anxiety and resilience among universities students in the Gaza Strip, after war on Gaza, and during a period of ongoing trauma exposure. The most commonly reported traumatic events were watching mutilated bodies on TV, witnessing the shelling and destruction of another's home, witnessing firing by tanks and heavy artillery at neighbors' homes, and being forced to move from home to a safer place during the war. Such findings were consistent with previous studies in the area [2-4]. Moreover, male students experienced significantly more traumatic events than females. Such gender differences toward males were consistent with results of similar studies in Gaza Strip [3]. Our finding that males reported more traumatic events than girls could be due to the cultural factors in which males are more active in daily life and political activities and that females are kept at home caring for other family members.

Our study showed that the anxiety state mean was 46.62 and anxiety trait mean was 36.2. There were no significant differences in anxiety state according to sex of the students. And there were significant differences in anxiety trait according toward the female students. Our results consisted with Mulatu study of 551 students in Ethiopia, which found that the mean of the scores on the Trait Anxiety scale was 45.40 and State Anxiety scale mean was 40.95 . In another study that drew upon the high prevalence rate of mental health problems among university students in Hong Kong, $21 \%$ out of 7,915 students were reported to have serious depression levels while $41 \%$ of these students were found with high levels of anxiety [21].

For resilience, the most common resilience items (most of the time/all the time) were: God can help (91.7\%) things happen for 
a reason (90.3\%), and being proud of their achievement $(85.2 \%)$ Mean resilience was 64.54 , personal competence was 20.99, trust in one's instincts was 15.32, positive acceptance was 13.18, control was 7.78, and spiritual influences' mean was 7.27. There were gender differences in resilience subscale. Male students had significantly more total resilience than females as well as more personal competence and more trust in one's instincts than females. The results showed a significant correlation between total traumatic events and anxiety state and trait. Our results were consistent with findings of Beiter et al. [22] in study of a sample consisted of 374 undergraduate students between the ages of 18 and 24 attending Franciscan University, Steubenville, Ohio which showed a statistically significant correlation between levels of depression, anxiety, and stress.

There was a positive significant correlation between anxiety state and total resilience and its subscales except in spiritual dimension. Campbell-Sills and colleagues [23] examined associations between personality characteristics and the CDRISC. With regard to the personality variables, the researchers found that the trait of neuroticism showed the strongest relationship with the CD-RISC, with extraversion displaying a slightly smaller relationship. Similarly, Bonelli et al. [24] reviewed 101 studies on the relationship between religious belief and psychological health and analyzed the stability of its relation with depression and anxiety and found that religious belief is helpful in reducing anxiety and depression by two thirds. Hartley [25] in study of a sample of 121 undergraduate students with mental health issues was recruited from campus mental health offices offering college counseling, psychiatric support, and disability support at two Midwestern universities, found that there was a significant interaction between mental health and intrapersonal resilience, indicating that the relationship between intrapersonal resilience and time to credits completed became stronger for students with the most elevated levels of psychological distress.

Lu et al. [9] investigated the prevalence of mental health problems and coping strategies in a sample of 1048 Chinese college freshmen from Shanghai. Religious belief was found to be significantly associated with depression and anxiety symptoms; contrary to previous findings which suggest that religious belief was a protective factor for psychological health $[26,27]$. Recently, Stanleya and Bhuvaneswarib [28] in a study conducted on undergraduate students of all three cohorts at a women's-only college in Tiruchirapalli in South India $(\mathrm{N}=73)$ assessing stress, anxiety, resilience and coping found that anxiety and stress levels were relatively higher in the first and third-year students while compared to those in the second year of their course, while resilience and coping was relatively low in the first year group. Correlations were significantly positive for the stress and anxiety scores as well as the coping and resilience scores. Such findings were consistent with Mancini et al. [29] in study of 368 female survivors of the Virginia Tech shootings completed assessments before the shooting, and at 2,6 and 12 months post-shooting, in which most individuals showed a resilient response (56-59\%), displaying low levels of anxiety and depression both before and after the shooting, some exhibited chronic distress and others a pattern of continuous high distress.

\section{Limitations of Study}

There are several limitations to our study. First, the crosssectional design precludes inferences about causality [30]. Second, mental health was assessed by self-reported questionnaires rather than structured diagnostic interviews. Although these instruments have been validated and shown to have acceptable sensitivity and specificity, as well as internal consistency, construct validity, and criterion validity, in a range of populations (including college students), these measures are not equivalent to clinical diagnosis. Future research should examine more Palestinian students to identify whether students' mental health problems are indeed as frequent as we suggest.

\section{Clinical Implications}

The findings of the current study suggest that undergraduate students need extra measures to deal with the anxiety and trauma that they experience [31]. Also, it is suggested that the academic lead (sta member) for the 1st-year cohort should meet with the whole group at least once a month to enable students to vocalize their difficulties and to seek clarification on various issues that they perceive to be difficult. Their anxieties usually revolve around clearing their final examination and any arrears (examinations not passed in the previous years) that add to their academic baggage, anxieties relating to whether to pursue a postgraduate degree or to explore vocational options. Meanwhile, preventive programs directed at strategies for the management of emotions should become a key component of university students' education [32]. The efficiency of psychological services, enhancement of physical exercise, promotion of extracurricular activities, thematic seminar and individual or group cognitive-behavioral therapy may contribute to promotion of good mental health. We suggest conducting awareness workshops for university student to learn more about impact of war on mental health. Also, to conduct awareness workshops for community members to learn more about psychological problems and their effects. Teach university student to use positive coping strategies in order to reduce potential psychological problems.

\section{References}

1. Kessler R, Sonnega A, Bromet E, Hughes M, Nelson CB (1995) Posttraumatic Stress Disorder in the National Comorbidity Survey. Arch Gen Psychiatry 52: 1048-1060.

2. Thabet AA, Tawahina A, El Sarraj EA, Vostanis $P$ (2008) Exposure to War Trauma and PTSD among Parents and Children in the Gaza Strip. Eur Child Adolesc Psychiatry 17: 191-199.

3. Thabet AA, AbuTawahina A, ElSarraj E, Vostanis P (2013) Death Anxiety, PTSD, Trauma, Grief, and Mental Health of Palestinians Victims of War on Gaza. Health Care Current Reviews 1: 2-8.

4. Thabet AA, Elheloub MW, Vostanis P (2015) Exposure to war traumatic experiences, post traumatic growth and resilience among university students in Gaza. Am J Adv Med Sci 1: 1-8.

5. Freh FM (2006) PTSD, Depression, and anxiety among young people in Iraq One decade after the American invasion. Traumatol 22: 56-62. 
6. Spielberger CD (1972) Anxiety-current trends and theory. NY: Academic Press, New York.

7. Reetz DR, Barr V, Krylowicz B (2013) The Association for University and College Counseling Center Directors Annual Survey.

8. Chen L, Wang L, Qiu XH (2013) Depression among Chinese university students: prevalence and socio-demographic correlates. PLoS One 8: e58379.

9. Lu W, Bian Q, Song YY, Ren JY, Xu XY, et al. (2015) Prevalence and Related Risk Factors of Anxiety and Depression among Chinese College Freshmen. J Huazhong Univ Sci Technol Med Sci 35: 815-822.

10. Richardson GE (2002) The meta theory of resilience and resiliency. J Clin Psychol 58: 307-321.

11. Cooper NS, Feder A, Southwick SM, Charney DS (2007) Resilience and vulnerability to trauma: Psychobiological mechanisms. In Romer D, Walker EF (Eds.), Adolescent psychopathology and the developing brain: Integrating brain and prevention science, NY: Oxford University Press, New York.

12. Morland LA, Butler LD, Leskin GA (2008) Resilience and thriving in a time of terrorism. In Joseph S, Linley PA (Eds.). Trauma, recovery, and growth: Positive psychological perspectives on posttraumatic stress. NJ: John Wiley, Hoboken pp: 39-61.

13. Bonanno GA (2004) Loss, Trauma, and Human Resilience Have We Underestimated the Human Capacity to Thrive After Extremely Aversive Events? Am Psychologist 59: 20-28.

14. DeHaan LG, Hawley DR, Deal JE (2013) Operationalizing family resilience as process: Proposed methodological strategies. In Becvar DS (Ed.), Handbook of family resilience, NY: Springer, New York.

15. Masten AS, Monn AR (2015) Child and Family Resilience: A Call for Integrated Science, Practice, and Professional Training. Family Relations 64: 5-21.

16. Lepore SJ, Revenson TA (2006) Resilience and posttraumatic growth: Recovery, resistance, and reconfiguration. In Calhoun LG, Tedeschi RG (Eds.), Handbook of posttraumatic growth: Research and practice. NJ: Erlbaum, Mahwah pp: 24-46.

17. Juma A, Thabet AA (2015) Relationship between stressors due to siege of Gaza Strip on anxiety, depression and coping strategies among university students. Arab J Psychiatry 25: 39-48.

18. Connor KM, Davidson JR (2003) Development of a new resilience scale: The Connor-Davidson Resilience Scale (CD-RISC). Depress Anxiety 18: 76-82.

19. Abdel-Khalek AM (1989) The development and validation of an Arabic form of the STAl: Egyptian results. Pers Individ Dif 10: 277-285.
20. Barnes LL, Harp D, Jung WS (2002) Reliability generalization of scores on the Spielberger State Trait Anxiety Inventory. Educational and Psychological Measurement 62: 603-618.

21. Wong JG, Cheung EP, Chan KK, Ma KK, Tang SW (2006) Web-based survey of depression, anxiety and stress in first-year tertiary education students in Hong Kong. Aust NZ J Psychiatry 40: 777-782.

22. Beiter $R$, Nash $R$, McCrady $M$, Rhoades $D$, Linscomb $M$, et al. (2015) The prevalence and correlates of depression, anxiety, and stress. J Affect Disord 173: 90-96.

23. Campbell-Sills L, Cohan SL, Stein MB (2006) Relationship of resilience to personality, coping, and psychiatric symptoms in young adults. Behav Res Ther 44: 585-599.

24. Bonelli R, Dew RE, Koenig HG, Rosmarin DH, Vasegh S (2012) Religious and spiritual factors in depression: review and integration of the research. Depress Res Treat 2012: 1-8.

25. Hartley MT (2013) Investigating the relationship of resilience to academic persistence in college students with mental health issues. Rehabil Couns Bull 56: 240-250.

26. Sisask M, Varnik A, Kolves K, Bertolote JM, Bolhari J, et al. (2010) Is religiosity a protective factor against attempted suicide: a crosscultural case control study? Arch Suicide Res 14: 44-55.

27. Schieman S, Bierman A, Ellison CG (2013) Religion and mental health. In: Aneshensel CS, Phelan JC, Bierman A, editors. Handbook of the Sociology of Mental Health. Springer, New York pp: 457-478.

28. Stanleya S, Bhuvaneswarib M (2016) Stress, Anxiety, Resilience and Coping in Social Work Students (A Study from India). Social Work Education 35: 78-88.

29. Mancini AD, Littleton HL, Grills AE (2016) Can People Benefit From Acute Stress? Social Support, Psychological Improvement, and Resilience After the Virginia Tech Campus Shootings. Clin Psychol Sci 4: 401-417.

30. Lazarus RS, Folkman S (1984) Stress, coping and adaptation. NY: Springer, New York.

31. Khamis V (2012) Impact of war, religiosity and ideology on PTSD and psychiatric disorders in adolescents from Gaza Strip and South Lebanon. Soc Sci Med 74: 2005-2011.

32. Song Y, Huang Y, Liu D, Kwan JS, Zhang F, et al. (2008) Depression in college: Depressive symptoms and personality factors in Beijing and Hong Kong college freshmen. Compr Psychiatry 49: 496-502. 